\title{
Multiple Cycle LES Simulations of a Direct Injection Natural Gas Engine
}

\author{
Martin Schmitt ${ }^{1}$ Rennan Hu${ }^{1}$ - Yuri Martin Wright ${ }^{1,2}$. \\ Patrik Soltic $^{3}$ - Konstantinos Boulouchos ${ }^{1}$
}

Received: 27 January 2015 / Accepted: 1 June 2015 / Published online: 4 July 2015

(C) Springer Science+Business Media Dordrecht 2015

\begin{abstract}
In this work the flow field evolution, mixture formation and combustion process in an engine with methane Direct Injection (DI) is investigated using Large Eddy Simulations. The supersonic methane injection is modeled according to Müller et al. (2013) and combustion by a level set approach. The flame propagation showed to be dependent on the grid resolution. Higher grid resolutions have two opposing effects: first the fraction of unresolved turbulence is reduced, which decrease the flame speed and second flame wrinkling is increased resulting in faster flame propagation. For the observed setup the wrinkling effect was stronger. The average in-cylinder pressure traces as well as the cyclic variability thereof were compared to experimental data and very good agreement was found. During the supersonic gaseous injection the turbulence level in the cylinder is significantly increased, which dissipates quickly and thus has only a minor effect on the flame propagation. The introduced momentum showed a larger impact, since it enhances the tumble motion resulting in increased turbulence levels as the tumble decays shortly before ignition. During DI the cyclic differences in the tumble motion are preserved, but the impact on the average tumble level results in changing relative differences of the cyclic turbulence levels at ignition timing. Thus an injection direction supporting the tumble flows is expected to reduce the Cycle-to-Cycle Variations (CCV), while a reduction of the tumble strength could increase the CCV level. Compared to the fluctuations in the turbulence levels, the cyclic variability of the equivalence ratio at the injection location with DI showed a minor effect on the simulated CCVs.
\end{abstract}

Martin Schmitt

martin.schmitt@lav.mavt.ethz.ch

1 Aerothermochemistry and Combustion System Laboratory, ETH, Zürich, Switzerland

2 Combustion and Flow Solutions GmbH, Zürich, Switzerland

3 Automotive Powertrain Technology Laboratory, Swiss Federal Laboratories for Materials Science and Technology (Empa), Dübendorf, Switzerland 
Keywords Large eddy simulation · Engine - G-equation · Multiple cycle simulation · Gaseous direct injection

\section{Introduction}

The reduction of $\mathrm{CO}_{2}$ emissions of internal combustion engines can be achieved by either increasing the efficiency, or by replacing the conventional crude-oil based fuels by alternatives with higher hydrogen to carbon ratios. A direct injection (DI) methane engine offers the possibility to combine both ways to lower $\mathrm{CO}_{2}$ emissions. Methane offers not only higher hydrogen content compared to conventional fuels, but also a higher knocking resistance which allows higher compression ratios and therefore increased efficiencies [2].

Simulations based on Reynolds Averaged Navier Stokes (RANS) approach are the most commonly used approach to simulate internal combustion engines. In particular direct injection gas engines have been investigated using RANS models in [3-6]. Gerke [4, 7] used a high resolution mesh to resolve the underexpanded jet and analyzed the mixture formation for different injection timings and RANS turbulence models. The results were validated against Planar Laser Induced Fluorescence (PLIF) measurements in a transparent engine. In [6], the jet is initialized downstream the Mach disk and the boundary conditions are derived from previous two dimensional simulations which fully resolve the jet. In general RANS provided very useful contributions towards understanding of gaseous direct injection engines, but also showed difficulties in predicting the physics for variable operating conditions or geometries. In addition the behavior of individual engine cycles cannot be investigated, since the RANS approach solves for ensemble averages [8].

In the last decade, Large Eddy Simulations (LES) are increasingly used to study the flow field in engines [8-10, 12]. A recent review of engine-related LES works can be found in Rutland [8], which gives a broad overview about pros and cons of different LES turbulence and combustion models. It is concluded that the grid requirements strongly depend on the chosen subgrid turbulence model. One of the first works using LES in a valve/piston assembly was published by Haworth [12]. The results were compared with Laser Doppler Anemometry (LDA) measurements and showed good agreement for the mean and the rms velocities. For a specifically designed optically accessible research engine, the groups of Poinsot and Angelberger published several papers which analyze flow and combustion in an homogeneous premixed engine (see, for example, $[9,10]$ ). The flame propagation is modeled based on an artificially thickened flame model. The simulation setup showed to be able to predict the cycle-to-cycle variations for two different operation points and the maximum pressure was found to correlate with the tumble center. Compared to Particle Image Velocimetry (PIV) measurements good agreement for the mean velocities was found, while small differences were observed in the fluctuation velocities. In the works $[13,14]$ the Extended Coherent Flame Model (ECFM-LES) was used to study the effect of local cyclic flow variations around the spark plug on the global cycle-to-cycle variations of the pressure traces. Further studies in the fields of cycle-to-cycle variations (CCV) by using LES have been conducted by Koch et al. [15]. In this work the subgrid turbulence is modeled by the $k-l$ model and combustion is simulated using G-equation. Up to 40 consecutive simulation cycles have been performed in order to analyze the CCV behavior in a perfectly premixed SI engine. Local dependencies around the spark plug region, which influence the early combustion stage and hence the CCV have been evaluated. It has been shown that the combination of the LES turbulence and G-equation combustion model is capable of accurately 
reproducing the experimentally measured CCV within a CFD simulation framework. According to Granet et al. [16] and Goryntsev et al. [11], up to 25 calculated cycles are required for the mean flow and 50 cycles for the cyclic fluctuations in order to get meaningful statistical results.

Studying gaseous DI numerically via LES, the direct injection process asks for a careful consideration of the complex physical phenomena during a supersonic gas expansion. At a certain pressure ratio between nozzle and combustion chamber downstream the nozzle orifice a sudden expansion of the injected gas can be observed. The thereby created expansion waves are reflected as compression waves leading to a vertical shock at defined distance from the nozzle. Experimentally [17] and analytically [18] it was shown that the shock position is mainly defined by the pressure ratio over the nozzle. Besides the location of the Mach disk also other structures of the underexpanded flow are well known. Most important structures beside the Mach disk are jet boundaries, barrel shocks and reflected shocks. A detailed description about the steady state, transient and mixing behavior of underexpanded jets at different pressure ratios is given in Vuorinen et al. [19]. The simulation of underexpanded jets in constant geometries is very challenging and an appropriate numerical treatment is required to accurately simulate the processes (e.g. shock capturing and specific turbulence model constants). If the underexpansion needs to be simulated in a full 3D engine setup the complexity is significantly increased, since some of the requirements for the simulation of underexpanded jets are in conflict which settings for a 3D-CFD engine calculations (e.g. locally extremely refined meshes and turbulence model settings).

In order to reduce this complexity Müller et al. [1] proposed a modeling methodology for gaseous direct injection systems. To incorporate the gas injection into full 3D Internal Combustion Engine (ICE) setups in an accurate and yet cost-efficient way, artificial inlet boundary (AIB) conditions have been developed. The AIB showed to be capable of accurately reproducing velocities, turbulence fields as well as methane concentrations after the Mach disk location. Compared to a detailed simulation the computational time has been decreased by a factor of 78 and the method showed to be especially suited for multiple cycle LES simulations.

In this work for the first time the injection model by [1] is introduced into a LES simulation setup of a four stroke gaseous direct injection engine described later. In the first part of this work the dependence of the subgrid turbulence model and the combustion model on grid resolution and discretization scheme is assessed. Based on these findings a method is proposed to readily derive combustion model constants for LES based on cheaper RANS simulations. The main aim of this paper is to investigate the influence of the gaseous injection on the engine performance. Thus, in the second part the influence of the direct injection on the global flow field in the cylinder is analyzed by comparing one cycle with and one without direct injection. After the comparison of the CCV with the experiment in the third part the influence of gaseous DI on the cycle to cycle variations is assessed in detail.

\section{Mathematical Formulation}

\subsection{Solver}

The flow field solver Star-CD v4.20 was employed to solve the compressible Navier-Stokes equations in a state of the art direct injection methane engine. The PISO algorithm is used for the pressure velocity coupling. 


\subsection{Turbulence models}

The RANS model is based on the standard $k-\varepsilon$ model, while in the LES model the subgrid turbulence is modeled with a one-equation $k-l$ model. According to [8] this LES turbulence model was found to incorporate more physical processes, such as the convection, production and dissipation of the subgrid kinetic energy, in comparison to the standard Smagorinsky turbulence model. Good results were also reported by Liu and Haworth [12] who compared the results of LES $k-l$ simulations with Laser Doppler Anemometry (LDA) measurements in a valve-piston assembly. The subgrid-scale stress tensor $\tau_{S G S, i j}=-v_{T} S_{i j}+\delta_{i j} \frac{2}{3} k_{S G S}$ is computed using the turbulent viscosity approach $\nu_{T}=C_{k} \bar{\rho} \Delta k_{S G S}^{1 / 2}$, where $C_{k}$ is a model constant, $S_{i j}$ the strain rate tensor, $\bar{\rho}$ the filtered density and $k_{S G S}$ is the subgrid-scale turbulent kinetic energy. Contrary to the more commonly used constant Smagorinsky approach where the $k_{S G S}$ is calculated from the strain rate tensor, the $k-l$ model employs a transport equation for $k_{S G S}$.

$$
\begin{aligned}
\frac{\partial \bar{\rho} k_{S G S}}{\partial t}+\frac{\partial \bar{\rho} \tilde{u}_{j} k_{S G S}}{\partial x_{j}}= & -\tau_{S G S, i j} \widetilde{S_{i j}} \\
& -C_{1} \bar{\rho} \frac{-k_{S G S}^{3 / 2}}{\Delta}+\frac{\partial}{\partial x_{j}}\left[C_{k} \bar{\rho} \Delta k_{S G S}^{1 / 2} \frac{\partial k_{S G S}}{\partial x_{j}}\right] .
\end{aligned}
$$

In the near-wall region a low Reynolds damping approach is used. For the RANS calculations an eddy viscosity model with a high Reynolds $k-\varepsilon$ formulation is used to simulate the turbulence and the near wall flow is modeled by a wall function, which is based on the law of the wall approach [20].

\subsection{Combustion model}

DI engines operate in the partially premixed combustion regime, where the extent of homogeneity depends strongly on the injection timing, duration and on the flow field. Two approaches are mainly used for turbulent and partially or fully premixed combustion in LES: In the artificially thickened flame model [21], the flame thickness is artificially increased in order to resolve the flame front by the mesh, while the flame propagation speed is left unchanged. The method has been successfully applied in several studies (see, e.g. [10, 22]), but has the drawback that the underlying physical process of flame propagation changes from a transport-controlled to a chemistry-controlled combustion mode [23]. The second option is the level-set approach, which is based on the G-equation proposed by Williams [24]. This model describes the flame front as an interface between burnt and unburnt gases, and a function $\mathrm{G}$ in introduced, whose $\mathrm{G}=\mathrm{G}_{0}$ isovalue represents the thin flame front, with $\mathrm{G}<\mathrm{G}_{0}$ in the unburnt gases and $\mathrm{G}>\mathrm{G}_{0}$ the burnt mixture. A transport equation for $\mathrm{G}$ in the LES context was derived by Peters [25], were $s_{T}$ is the turbulent flame speed defined as a function of the turbulence intensity $u^{\prime}$ and the laminar flame speed $s_{L}$. The laminar flame speed is calculated based on the equation of Gülder [26]. The previously described equations are:

$$
\begin{gathered}
\frac{\partial}{\partial t} \bar{\rho} \tilde{G}+\frac{\partial}{\partial x_{i}} \bar{\rho} \tilde{u_{i}} \cdot \nabla \tilde{G}=\bar{\rho} s_{T}|\nabla \tilde{G}| \\
s_{L}(\Phi)=Z W \Phi^{\eta} \exp \left[-\xi(\Phi-1.075)^{2}\right]\left(\frac{T_{u}}{T_{0}}\right)^{\alpha}\left(\frac{p}{p_{0}}\right)^{\beta}\left(1-f f Y_{E G R}\right)
\end{gathered}
$$




$$
\begin{gathered}
s_{T}(\Phi)=s_{L}(\Phi)\left[1+A\left(\frac{u^{\prime}}{s_{L}(\Phi)}\right)^{5 / 6}\right] \\
s_{T}=\int_{0}^{1} s_{T}(\Phi) P(Z) d Z
\end{gathered}
$$

where $W, \eta, \xi, \alpha, f f$ and $\beta$ are fuel dependent model constants and $Y_{E G R}$ is the mass fraction of the residual (burnt) gases. The values for methane are given in [27] and the subscripts 0 and $u$ denote reference and unburnt gas properties. The fluctuation velocities $u^{\prime}$ are computed from the turbulent kinetic energy $u^{\prime}=\left(\frac{2}{3} k\right)^{1 / 2}$, and is therefore dependent on the unresolved scales and thus on mesh resolution. In RANS, $k$ represents all turbulent scales, while in LES the contribution of resolved scales is accurately captured and the subgrid part $k_{S G S}$ is modeled. The constant $A$ has to be defined by the user to adjust the turbulent flame speed according to experimental data and $\phi$ represents the equivalence ratio. For $P(Z)$ the Beta PDF has been parameterized by its first two moments, namely the mixture fraction and its variance which are determined by solving the two corresponding transport equations [27].

In this work ignition is initiated by modifying the value of $G$ within a specified radius around the spark plug at spark advance. Similar approaches have been successfully adopted also in other multi-cycle LES studies (see e.g. $[10,15,28]$ ) and therefore used here as well. More sophisticated approaches have been proposed in the LES context in conjunction with Flame Surface Density combustion models $[29,30]$ and for level sets in a RANS context in [31]. Despite the simplicity of the ignition treatment used in this study, using an appropriate flame kernel radius and sparking duration, good agreement in the pressure rise of the mean cycle can be achieved after ignition, i.e. up to $700{ }^{\circ} \mathrm{CA}$. Following this calibration, using an unchanged ignition treatment for all cycles, the variation in the pressure evolutions can then be predicted, in good agreement with the experimental data; as was also found in [15] for a completely different engine.

\section{Engine Setup and Numerical Model}

\subsection{Engine configuration and operating point}

The engine under consideration is a state of the art boosted gasoline direct injection (DI) engine which is modified for DI of gaseous fuels by means of custom-made injectors. It has four cylinders, a total displacement of 1.41 and a compression ratio of 9.6. The fuel used is pure methane stored in high-pressure cylinders and provided, using a 34 bar pressure regulator, via a gas rail to the injectors [32]. Figure 1 shows a photograph of the engine's air-side as it was mounted at the test bench. The full engine geometry at BDC as well as the position of the multi-hole injection system is indicated in Fig. 2. The fuel enters the cylinder through six nozzle orifices, each with a diameter of $0.75 \mathrm{~mm}$. The studied operating point is in the part load range at an engine speed of $2000 \mathrm{rpm}$ and a mean effective pressure (BMEP) of 2 bar. The fuel is injected from $540{ }^{\circ} \mathrm{CA}$ to $547{ }^{\circ} \mathrm{CA}$. At this time the inlet valve is still open, resulting in a backflow of fuel into the intake channel for the observed operating point. The spark ignition occurs shortly before reaching TDC at $699.8^{\circ} \mathrm{CA}$. The main characteristics of the experimental setup are summarized in Table 1. 


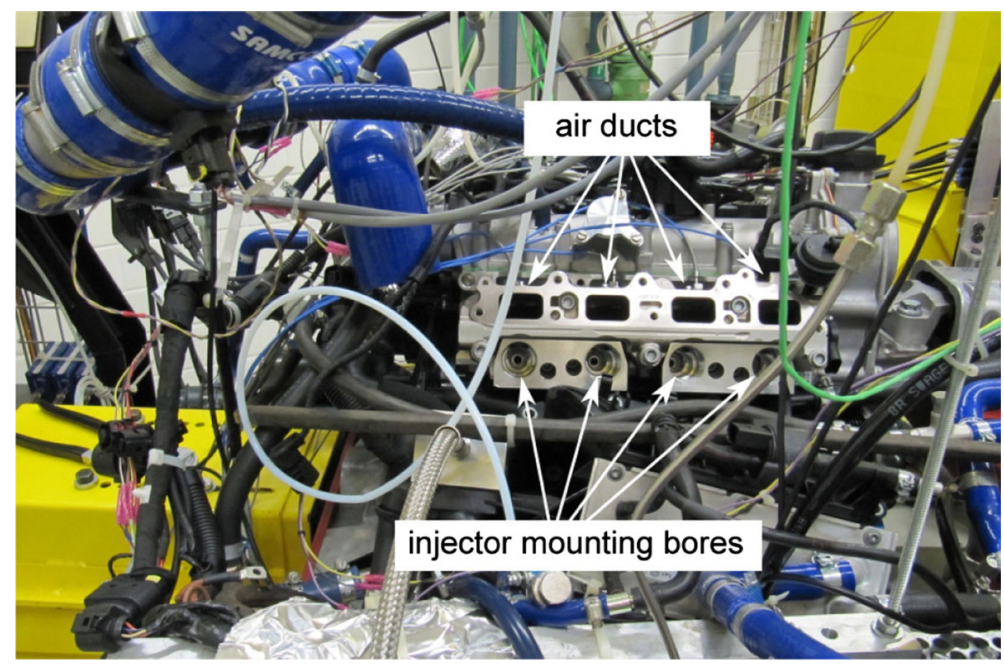

Fig. 1 Air-side of the engine at the test bench with dismounted intake manifold and dismounted injectors

\subsection{Mesh models}

Two meshing methods and cell types are applied to construct the computational grid. For the cylinder, the exhaust and valve area, the Star-CD plugin es-ice is used to create a hexahedral mesh that accounts for the complex geometry movement of the piston and valves. For the inlet channel, a polyhedral grid including prism layer was created using the meshing software Star-CCM+. Furthermore, the injector mesh region has been refined in Star-CCM+ according to the mesh settings proposed by Müller et al. [1] in order to correctly reproduce the flow field quantities of the gas injection (Fig. 3). This approach allows fast geometry changes, which can be used for parameter variations in order to optimize the injector and inlet geometry.

The full compuational mesh is shown in Fig. 2. The engine mesh consists of approximately 1.53 million cells at BDC, which results in an average cell size of $0.65 \mathrm{~mm}$. Mesh resolutions from comparable studies, where multiple cycle [10, 15] and spray behavior [33] in internal combustion engines are analyzed provided a mean grid size of approximately 0.8 and $1.2 \mathrm{~mm}$, respectively. Further mesh details are shown in Table 2. A single cycle simulation running on $128 \mathrm{CPUs}$ takes about $48 \mathrm{~h}$ of computational time. The calculation time within a cycle is distributed as follows: intake and exhaust $=31 \%$, injection $=34 \%$, compression $=9 \%$, combustion $=26 \%$.

In the first part of this study a grid sensitivity analysis has been conducted. Based on the basic mesh described before, two refined grids with mean average cell sizes of 0.55 and $0.45 \mathrm{~mm}$ have been created. In order to reduce the computational time, the meshes in the resolution study are employed as half cylinder meshes. According to Koch et al. [15], the effect of the symmetry boundary condition is limited, since in this setup the tumble around the $\mathrm{x}$-axis and the swirl are negligible small. In addition, the half cylinder meshes are only used for the LES and G-equation model analysis in Section 4.1.1.

For the assessment of the jet influence, the comparison with experimental data and the multiple cycle analysis the previously described full engine mesh is used. 


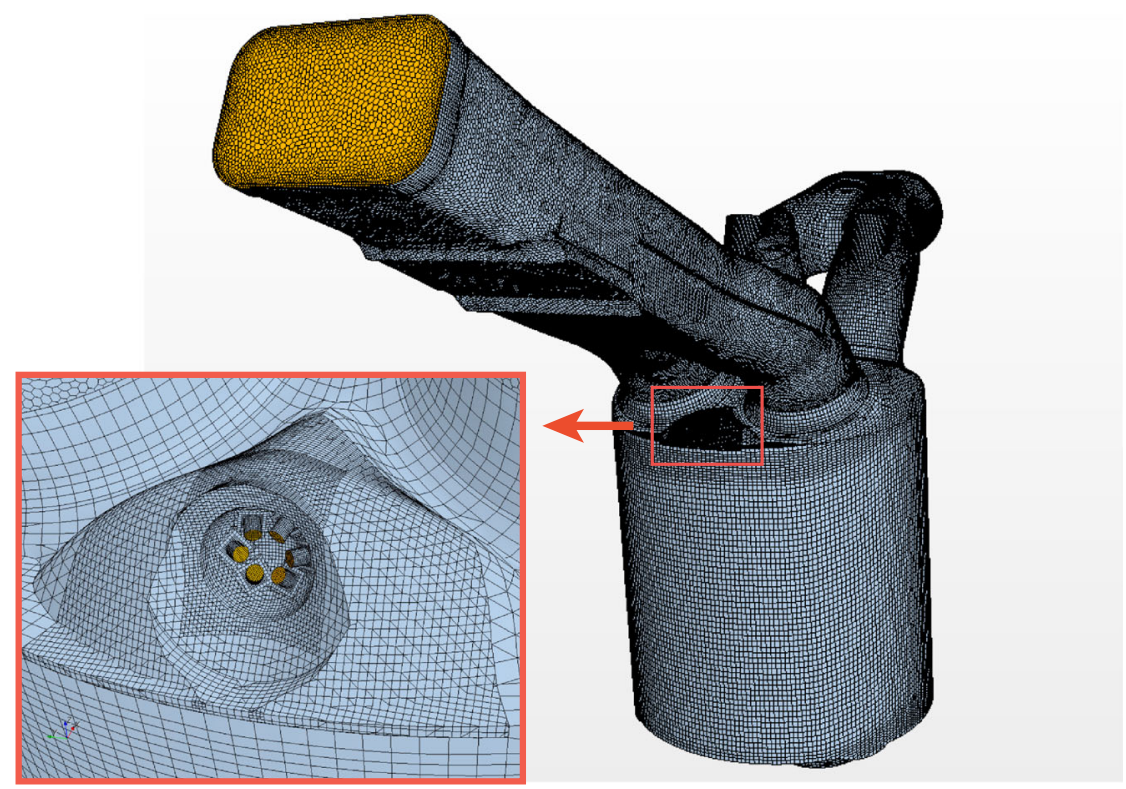

Fig. 2 Four valve passenger car engine with central spark plug and multi-hole injector with highlighted boundary conditions for intake and injector (orange) as well as exhaust

\subsection{Boundary and intitial conditions}

Pressure and temperature boundary conditions were imposed at the inlet and outlet surfaces (as highlighted in Fig. 2) using tabulated data obtained from a separate 1D GT-Power simulation (Fig. 4) validated by experimental measurements. Fontanesi et al. [34] investigated the effect of boundary condition on the CCVs of a turbocharged GDI engine using LES. They compared the influence of a cycle-independent pressure condition derived from a 1D

Table 1 Main characteristics of the experimental setup

\begin{tabular}{llll}
\hline Engine & \multicolumn{3}{l}{ Operation point } \\
\hline bore & $76.5 \mathrm{~mm}$ & speed & $2000 \mathrm{rpm}$ \\
stroke & $75.6 \mathrm{~mm}$ & BMEP & $2 \mathrm{bar}$ \\
compression ratio & 9.6 & SOI / EOI & $540 / 547{ }^{\circ} \mathrm{CA}$ \\
fuel injection & $\mathrm{CH}_{4} \mathrm{DI}$ & spark ignition & $699.8^{\circ} \mathrm{CA}$ \\
nozzle diameter & $0.75 \mathrm{~mm}$ & pinj & $34 \mathrm{bar}$ \\
number of nozzles & 6 & Fuel-air ratio $\phi$ & 1 \\
& & & \\
Test bench & & Pressure indication & \\
type & Horiba Dynas LI250 & Crank angle sensor & Kistler, resolution $0.1^{\circ} \mathrm{CA}$ \\
automation & $\mathrm{SRH} \mathrm{STARS}$ & pressure sensor & Kistler $6061 \mathrm{~B}$ \\
air conditioning & $23{ }^{\circ} \mathrm{C}, 50 \% \mathrm{RH}$ & charge amplifier & Kistler 5064 \\
\hline
\end{tabular}



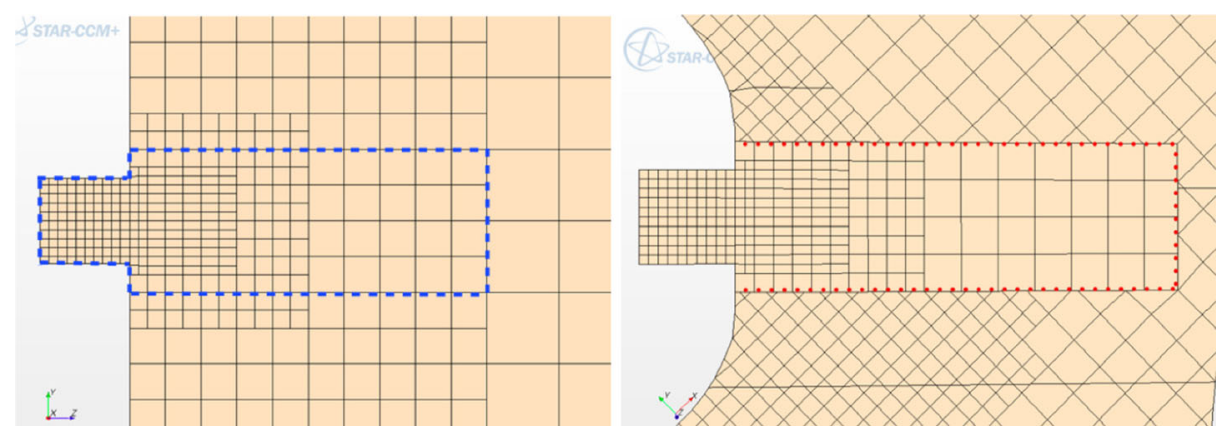

Fig. 3 Adaptation of the simple box mesh structure (left) within the full engine mesh model (right)

engine model and cycle-dependent experimental pressure traces. Since no significant differences between both approaches could be observed, it was concluded that LES is capable of capturing the port fluctuations when using a mean pressure boundary formulation.

The methane injection through the six nozzle orifices is modeled by the artificial inlet boundary condition (AIB). In order to prevent initial high gradients when opening or closing the AIBs, an exponential ramp function has been used to gradually decrease or increase the incoming methane mass flow representing the opening/closing event of the real injector.

The simulation is initialized shortly before the charge exchange top dead center at $340{ }^{\circ} \mathrm{CA}$ in order to simulate the full intake process to derive reasonable initial conditions for the compression and combustion for the single cycle analysis. In case of the multi-cycle calculation, the influence of the initial conditions becomes small after two cycles according to Koch et al. [15]. The cylinder is initialized with a temperature of $1143 \mathrm{~K}$ and a pressure of $1.077 \mathrm{bar}$, the intake port with $333 \mathrm{~K}$ and 0.464 bar and the exhaust port with $1058 \mathrm{~K}$ and 1.071 bar. The initial pressure and temperature values are estimated based on the 1D GT-Power Simulation. The intake port is initialized with pure air whereas the cylinder and outlet channel consist of fully burnt exhaust gases.

At the isothermal wall boundaries fixed temperatures based on the 1D GT-Power Simulation are imposed. The temperatures of the cylinder liner, the piston face and the cylinder head are set to $523 \mathrm{~K}$, at the intake region to $380 \mathrm{~K}$ and the exhaust port to $475 \mathrm{~K}$. In terms of the half cylinder model, a symmetry boundary condition has been used at the mid plane section. The near-wall region is refined by a single layer of prism cells and the wall heat losses are calculated through the Angelberger correlation [27].

\subsection{Numerical settings}

A second order monotone advection and reconstruction discretization scheme (MARS) has been used for the momentum, energy and turbulence equations in the context of cold flow simulations. The reactive calculations used a first order scheme to discretize the energy and turbulence equations, to avoid numerical instabilities occurring at the inlet and exhaust

Table 2 Mesh specifications

\begin{tabular}{llllll}
\hline Mesh & Intake Cells & Injector Cells & Cells at TDC & Cells at BDC & CPUh per cycle \\
\hline Full Cylinder & 411.000 & 67.000 & 954.000 & 1.533 .000 & 6144 \\
\hline
\end{tabular}



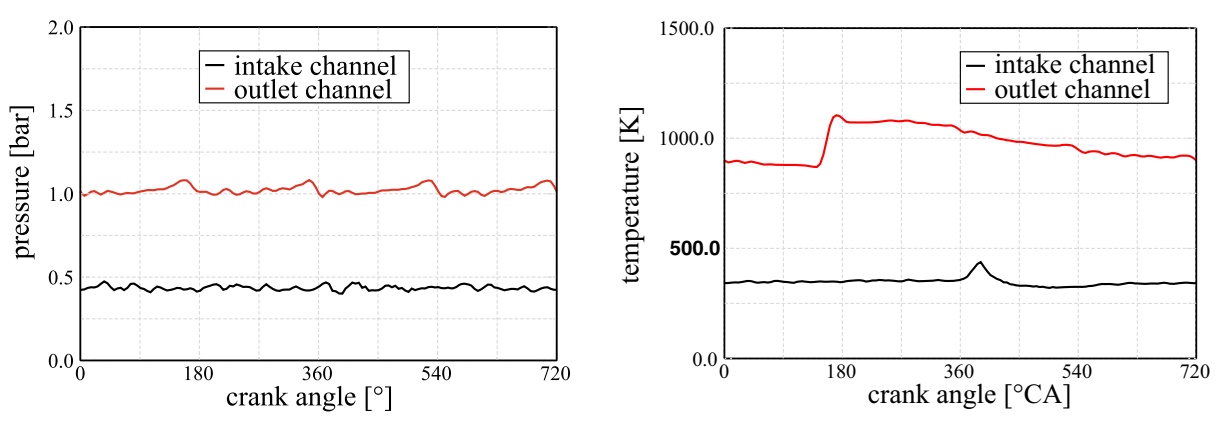

Fig. 4 Pressure and temperature boundary conditions in the inlet and outlet channel

valve opening or closing. The basic time step of $0.2^{\circ} \mathrm{CA}$ is reduced during combustion and injection to $0.02{ }^{\circ} \mathrm{CA}$ and $0.0025^{\circ} \mathrm{CA}$, respectively.

\section{Results}

The first part focuses on the LES and G-equation model analysis using different mesh configurations and discretization schemes. Furthermore, the influence of the gaseous direct injection on the mean and fluctuating flow field are illustrated. The second part shows the comparison of experimental and calculated results such as pressure traces or coefficient of variation.

\subsection{Single-cycle simulations}

In a first step initial cold-flow and reactive simulations have been conducted on the half cylinder model to investigate the interaction of the LES turbulence and G-equation combustion model in terms of grid sensitivity as well as influence of discretization schemes. The second Section 4.1.2 discusses the influence of the newly implemented gaseous direct injection on the overall in-cylinder flow field.

\subsubsection{Assessment of the LES and the combustion model}

Cold-flow and reactive cases have been calculated on three different meshes to investigate the influence of the mesh resolution on the results. In addition the influence of discretization schemes is assessed and a comparison between RANS and LES has been carried out. Figure 5a shows a comparison of the simulated volume averaged subgrid-scale turbulent kinetic energy $\left(k_{S G S}\right)$ in non-reactive cases computed with the three mesh resolutions. Before the inlet valve opening at $375^{\circ} \mathrm{CA}$, all meshes show very low and similar $k_{S G S}$ values. After the opening of the inlet valve air flows into the cylinder resulting in the increasing $k_{S G S}$ values. With up to $40 \mathrm{~m}^{2} / \mathrm{s}^{2}$ the coarse grid shows the highest values compared to other meshes, which can be explained due to the lower amount of kinetic energy resolved by the grid. In contrast to this, the difference between the middle and the fine mesh is very small, although the fine mesh is able to resolve more turbulent scales. In order to understand this behavior Fig. 5 b shows the total kinetic energy $\left(k_{S G S}+0.5 *\left(\widetilde{u}^{2}+\widetilde{v}^{2}+\widetilde{w}^{2}\right)\right)$. In general all investigated meshes show a similar temporal evolution. Interesting is the increased total kinetic energy in the fine grid at $390{ }^{\circ} \mathrm{CA}$ which is $7 \%$ higher compared to the lower 

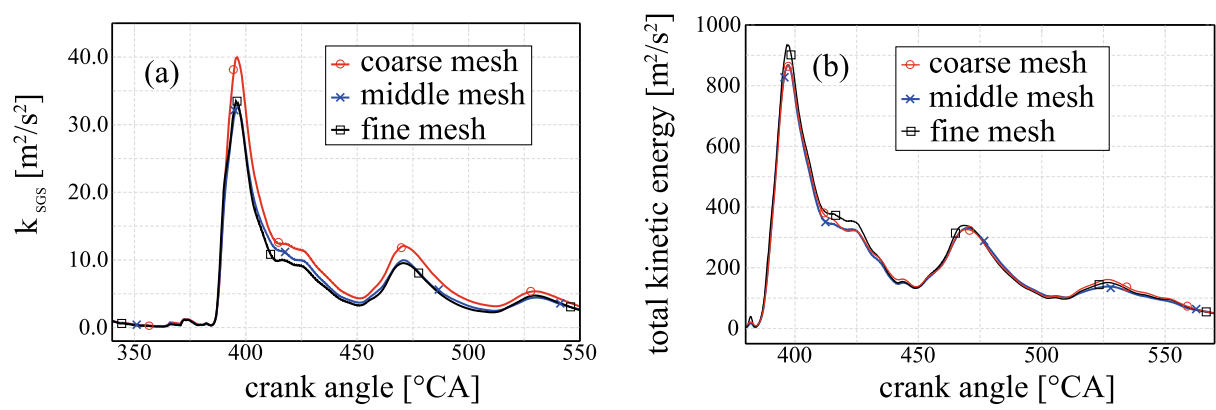

Fig. 5 Comparison of the cylinder averaged subgrid-scale turbulent kinetic energy (a) and total kinetic energy (b) between three mesh resolutions

resolution meshes. Since the $k_{S G S}$ values between the middle and the fine mesh are nearly the same, the simulation in the fine mesh calculates a higher amount of turbulent energy.

To get a better understanding of why the cylinder averaged $k_{S G S}$ between the medium and the fine mesh are very similar and the fine mesh has a higher total kinetic energy, Fig. 6 shows the velocity magnitude on a slice of all three calculated meshes during the inlet phase. At $450{ }^{\circ} \mathrm{CA}$ the inlet valve is open and air enters the combustion chamber. Between coarse and middle mesh the scales of the velocity field look very similar. In contrast to this, the fine mesh is able to resolve much smaller flow structures. The jet breakup is much stronger and responsible for the creation of small turbulent scales. This behavior explains also the similar $k_{S G S}$ shown in Fig. 5a. Smaller scales lead to higher velocity gradients and since the production term in Eq. 1 is dependent on $S_{i j}$, more $k_{S G S}$ is produced.

Figure 7 shows the $k_{S G S}$ during the inlet phase computed on the coarse grid by different discretization schemes. The lower $k_{S G S}$ values obtained with lower discretization order methods can be attributed to the smoothing effect of the lower order schemes. Figure 7a shows the spatial $k_{S G S}$ separation on the calculation with first order solved turbulence and energy equation. Compared to Fig. $7 \mathrm{~b}$, where all equations are solved second order, the magnitude is smaller and the local structures appear much smoother. For the global flow field, the influence of the differences is quite small but they could have a strong effect on the calculation of the turbulence-flame interaction, since $k_{S G S}$ is directly connected to the turbulent flame speed $\mathrm{s}_{T}$ (see Eq. 4).
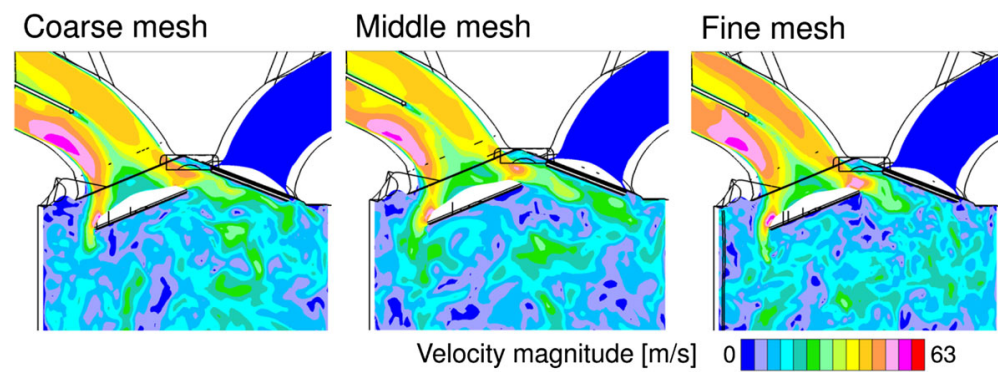

Fig. 6 Velocity magnitude distributions on a slice through the valves for different mesh resolutions at $450{ }^{\circ} \mathrm{CA}$ 

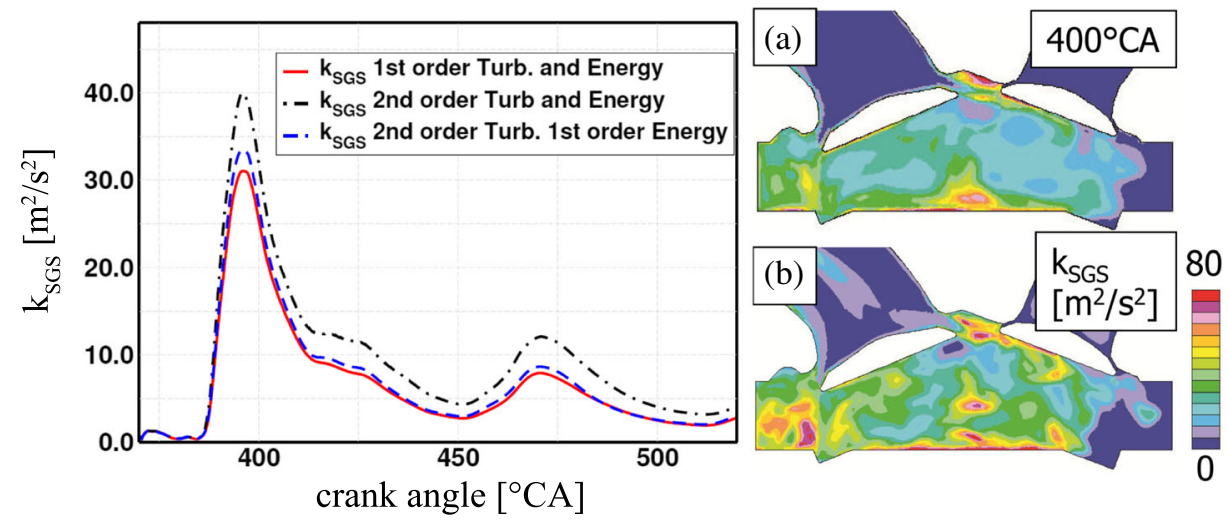

Fig. 7 Influence of the discretization scheme on the modeled $k_{S G S}$ volume averaged in the cylinder on the coarse grid. a shows the spatial separation of $k_{S G S}$ on a plane through the valves at $400{ }^{\circ} \mathrm{CA}$ with 1 st order solved turbulence and energy equation and $\mathbf{b}$ with fully 2 nd order solved equations

Figure 8 compares the averaged pressure curves of the RANS and LES calculations on the coarse grid using different $A$ factors in Eq. 4. For the same value of $A$, the pressure curve predicted by the RANS is much higher than the value obtained by the LES.

This is due to the different definitions of the turbulent kinetic energy $k$ in RANS and LES. It was found by trial and error that by using a factor $A=7.5$ in the LES, comparable pressure curves as for the RANS can be obtained. The LES simulation was adapted to the RANS calculation because the G-equation model is commonly used in an RANS context and for this $A=2.8$ is a typical value for the constant in Eq. 4. In contrast to this LES

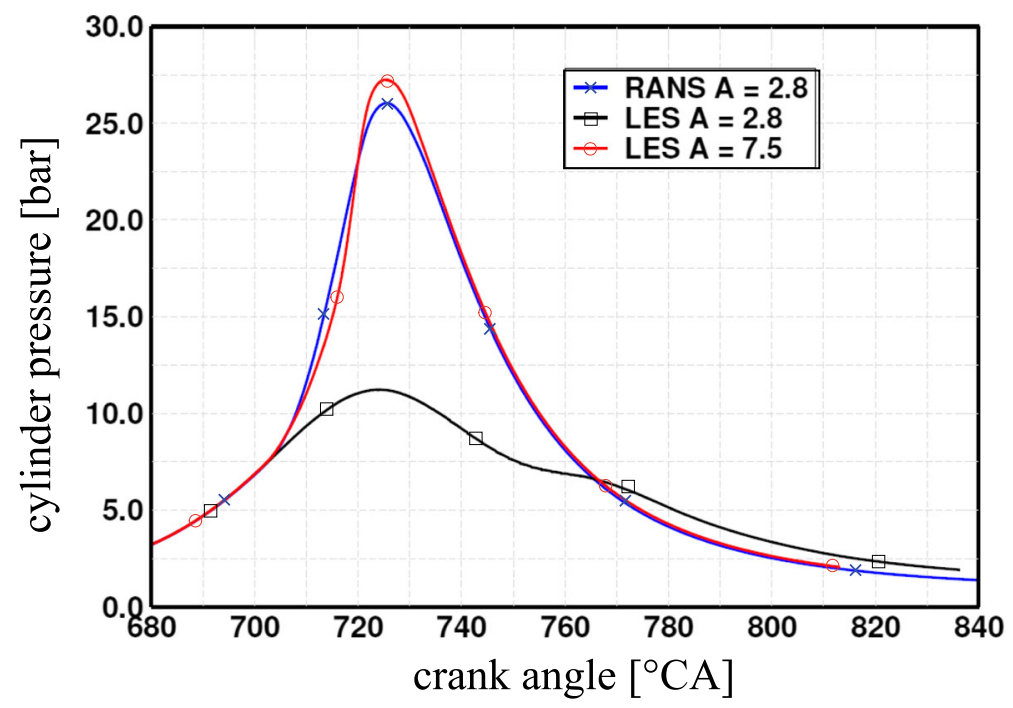

Fig. 8 Pressure curves from RANS and LES calculations on the coarse grid with different A factors 


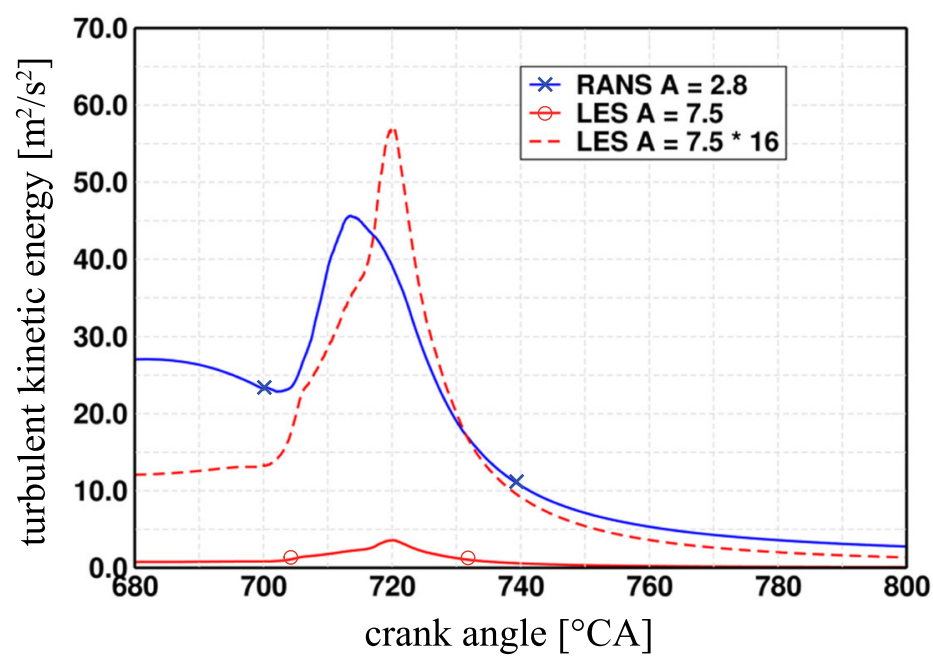

Fig. 9 Comparison of the turbulent kinetic energy $(k)$ in RANS and the subgrid-scale turbulent kinetic energy $\left(k_{S G S}\right)$ in LES on the coarse grid volume averaged in the cylinder for different values of the Damköhler constant A

in combination with G-equation has to our knowledge not been documented in the open literature for internal combustion engine calculations and therefore $A$ is a priori unknown, since $k_{S G S}$ represents only the fraction of the $k$ which cannot be resolved. A better way to derive the correction factor for LES is shown in Fig. 9, comparing $k$ with $k_{S G S}$. The dotted red line $\left(k_{S G S}\right.$ scaled by 16$)$ overall agrees with the turbulent kinetic energy of the RANS calculation reasonably well.

If the ratio of $k$ and $k_{S G S}$ is known, Eq. 4 can be used to compute the scaling factor between $\mathrm{A}_{R A N S}$ and $\mathrm{A}_{L E S}$, which in this case is 2.68. Thus, the factor $A$ for the turbulent flame speed can be computed directly from the comparison of the turbulent kinetic energy in the cylinder. The ratio of $k$ and $k_{S G S}$ can be derived by a single cycle RANS and LES calculation, which greatly reduces the CPU time in terms of tuning compared to a trial and error approach where several calculation are needed. The described approach does not aim at deriving an A factor for the LES calculation which results in the same turbulent flame speed value compared to the RANS calculation. This can be seen in Fig. 9 showing at ignition timing (700 $\left.{ }^{\circ} \mathrm{CA}\right)$ a $k_{S G S} * 16$ value, which is around $42 \%$ smaller than the corresponding turbulent kinetic energy of the RANS calculation. This results in a slower turbulent flame speed of the LES calculation. But as will be shown in Fig. 11 the flame area of the LES is significantly larger (also around $40 \%$ ) compared to the RANS calculation, resulting as shown in Fig. 8 in a similar overall flame propagation of the RANS and the LES calculation. Thus when determining the A factor based on the RANS calculation, based on the given information on the ratio of the flame area as function of the grid size the A factor for the LES calculation can be estimated.

The mean and instantaneous temperature fields computed by RANS and LES plotted in Fig. 10 show again the ability of LES to provide additional details of the wrinkled propagating flame compared to the smooth averaged front. At higher mesh resolution, the flame front area is also found to increase, because of the higher amount of resolved turbulence. 

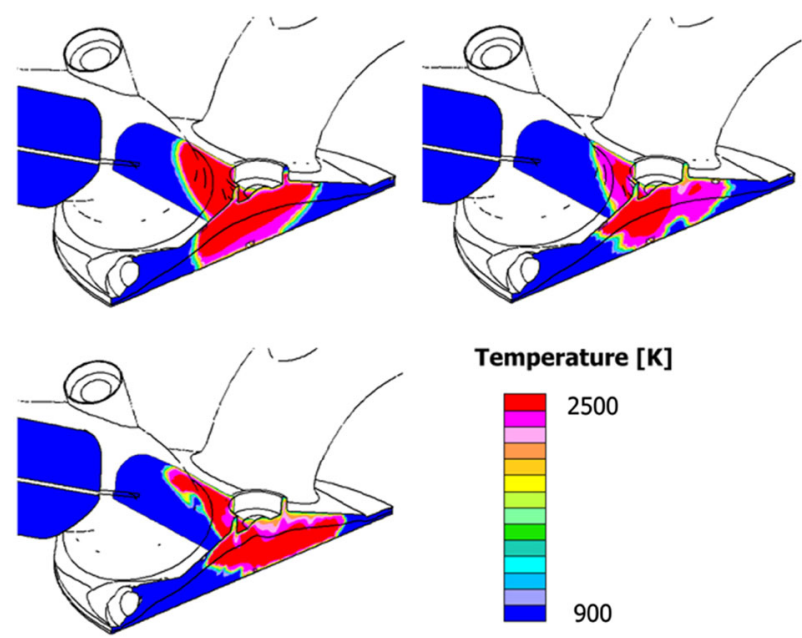

Fig. 10 Temperature field of the coarse mesh with RANS (top left) and LES (top right) and of the fine mesh with LES (bottom left) at $710^{\circ} \mathrm{CA}$. The section planes are orthogonal to the cylinder axis

In order to quantify the differences between the simulations of the flame front wrinkling, the flame area, defined by the temperature iso-surface at $1500 \mathrm{~K}$, from the different simulations is shown in Fig. 11. As expected, the smallest flame area is computed by RANS. The flame area calculated in the LES simulations is higher and increases with resolution since the finer turbulence structures that can be accommodated result in additional wrinkling of the propagating front.

The larger flame area also affects the turbulent flame speed, because $\mathrm{s}_{T}$ is defined normal to the flame front. For this reason, the A-factor in the fine mesh is 5 and therefore smaller compared to the coarse mesh. One interesting observation of the interaction between

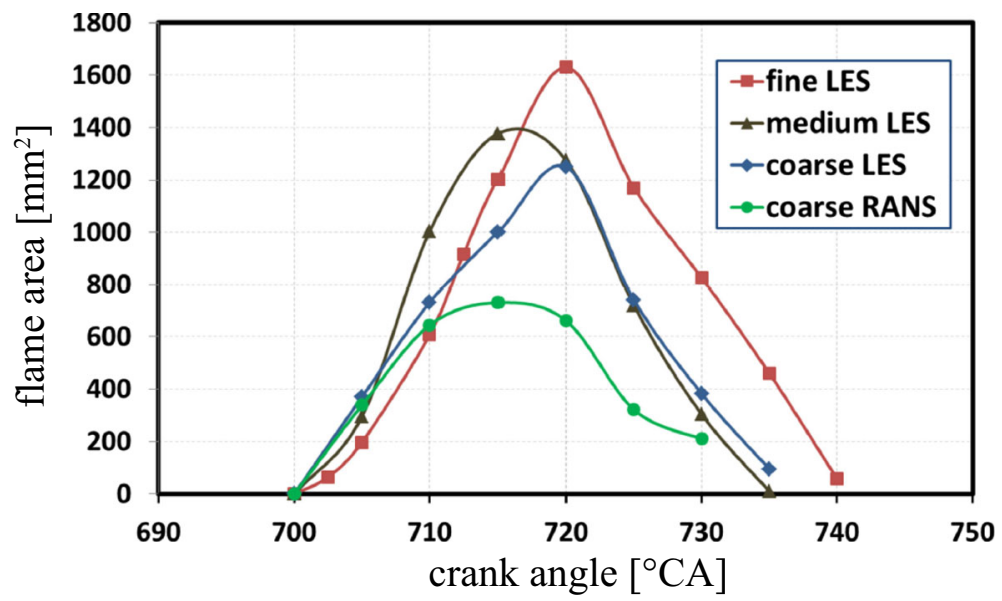

Fig. 11 Comparison of the flame area evolution from RANS and LES simulations with different grid resolutions 
LES and G-equation model can be seen when comparing the RANS and LES simulation in the Figs. 9 and 11. In Fig. 9 at $700^{\circ}$ the turbulent kinetic energy in case of RANS is approximately twice as high as the corresponding LES value which results in higher turbulent flame speeds according to Eq. 4. However, as seen in Fig. 11, the peak values of the flame areas reached during combustion of the LES simulation is almost double the RANS area and the mentioned deficit in turbulent kinetic energy is hence compensated to some extent. In summary, a higher mesh resolution coupled with G-equation and LES has two effects on the calculation of the flame speed. First, $k_{S G S}$ decreases (due to the increase of the resolved turbulence scales) and as a consequence of the employed closure $\mathrm{s}_{T}$ reduces as well. Secondly, the flame area increases, which accelerates the flame. So for a mesh, which fully resolves all turbulent scales, no closure for the flame-turbulence interaction is needed any more. For the observed setup the wrinkling effect was stronger and thus the resulting flame propagation showed to be slightly dependent on the grid resolution.

In conclusion the simulation setup used in this work depends on validation based on experiments in order to adjust the constants for the relatively simple combustion and ignition models. Possible model improvements could be done by using a more sophisticated closure for the turbulent flame speed as proposed e.g. in [23]. However, as shown later in this work and in Koch et al. [15] the proposed methodology showed to be able to accurately predict the cyclic variability of the pressure traces, requires relatively low computational resources and thus is well suited to study the effect of gaseous direct injection on the cyclic variability.

\subsubsection{Influence of gaseous DI on the in-cylinder flow field}

The gaseous fuel injection has been modeled through the AIB method proposed by Müller et al. [1]. The suggested step by step guideline has been followed to derive the inlet boundary condition for the existing injector nozzle geometry and engine operating point. The detailed tuning steps for deriving the AIB constants are described in the Appendix 1.

Figure 12 shows the methane mixing behavior during the compression stroke by means of $\mathrm{CH}_{4}$ mass fraction contour plots at $547^{\circ} \mathrm{CA}, 560^{\circ} \mathrm{CA}$ and $701{ }^{\circ} \mathrm{CA}$. A methane mass fraction value of 0.055 depicts stoichiometric conditions. At $547^{\circ} \mathrm{CA}$ shortly before EOI, it can be seen that the fuel injected by the upper nozzle orifices partly flows into the intake manifold since for the chosen injection timing the intake valves are open during injection. The

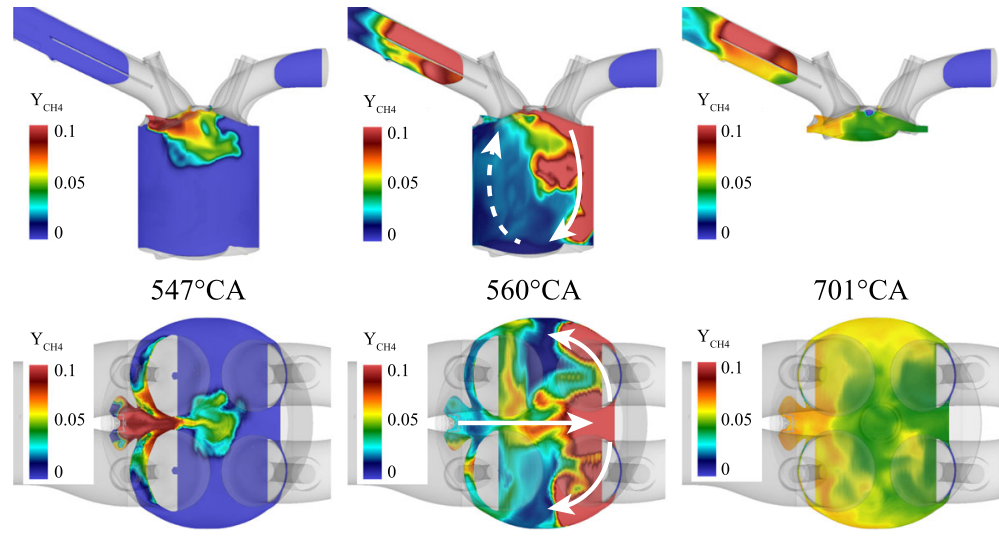

Fig. 12 Transient evolution of methane mass fraction within the cylinder during 2nd cycle 
remaining fuel is directed along the pent roof to the central spark plug region. At $560{ }^{\circ} \mathrm{CA}$, the methane jet has impinged on the cylinder walls at the exhaust valve sides forming two recirculation zones. Furthermore, the injected fuel is carried along by the tumble flow motion down towards the piston head region. The dashed arrow on the intake valve side, indicates the further transport of the fuel rich zone by the tumble motion. The escaped methane portion is stored within the intake manifold and rebreathed within the consecutive engine cycle. At $701{ }^{\circ} \mathrm{CA}$ shortly after ignition timing a non-homogeneous mixture composition can be noticed. A fuel rich zone can be seen on the intake valve side of the cylinder while on the exhaust side lower fuel concentrations can be observed. The distribution is a result of the tumble motion which during compression transports the fuel rich zone back to the injector position. Thus a better mixture homogenization can be achieved by e.g. activating the tumble flap within the intake in order to strengthen the tumble motion for the given part load operating point, which can lead to a better mixture homogenization.

In order to quantify the temporal evolution of the in-cylinder mixture condition, the probability density function (PDF) of the methane mass fraction in the whole cylinder is shown in Fig. 13. At EOI, the majority of cells contain almost no fuel fraction, whereas a minority of cells mainly consist of methane. Due to the in-cylinder bulk flow motion, the fuel is distributed within the combustion chamber resulting in the decay of the existing first peak. At $680^{\circ} \mathrm{CA}$ methane has been distributed within the whole cylinder forming a second peak, which is close to stoichiometric mixture conditions. The tumble breakdown towards TDC decelerates the mixing process, which explains the marginal difference in the shape of the PDFs between $680^{\circ}$ and $701{ }^{\circ} \mathrm{CA}$. Thus, the mixture shortly after ignition timing is still not perfectly homogeneous as depicted by the bandwidth of the green curve.

Large scale flow motions can be described by the tumble level which is expressed with respect to the center of mass of the cylinder according to the following equation:

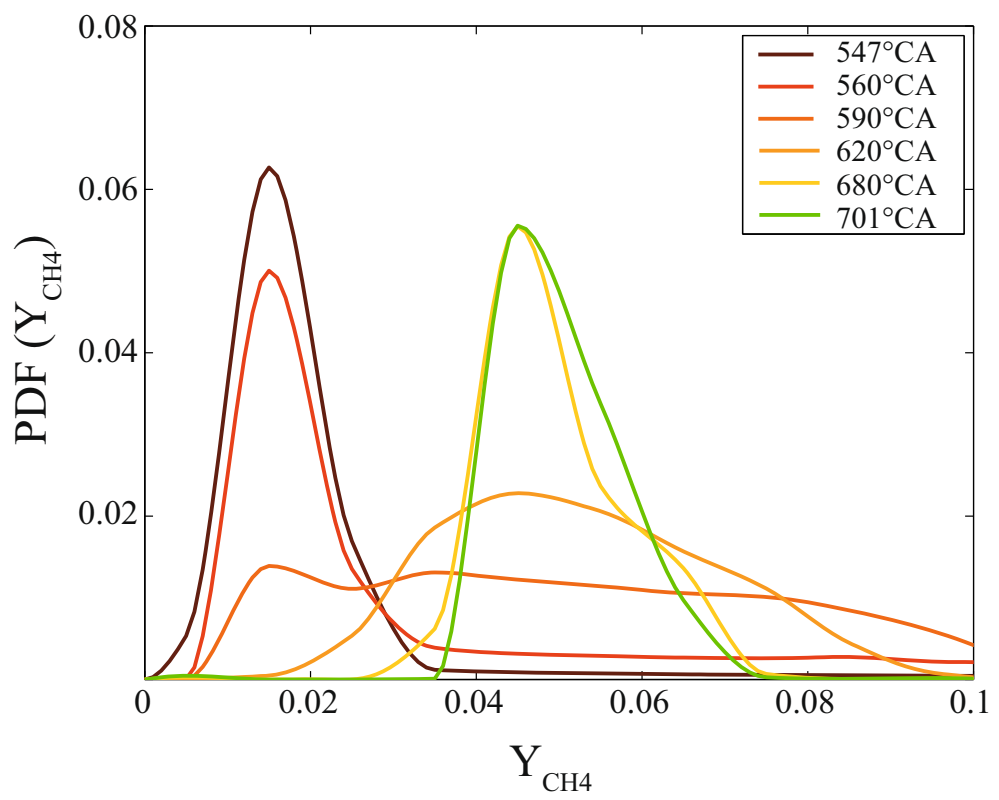

Fig. 13 Probability density function of methane mass fraction during 2 nd cycle 


$$
\text { TumbleY }=\frac{\sum_{\text {Cells }} \rho_{i} V_{i}\left[\left(Z_{i}-Z_{m}\right) u_{i}-\left(X_{i}-X_{m}\right) w_{i}\right]}{\sum_{\text {Cells }} \rho_{i} V_{i} \sqrt{\left(Z_{i}-Z_{m}\right)^{2}+\left(X_{i}-X_{m}\right)^{2}}}
$$

where $X_{i}, Z_{i}$ are the centroid coordinates of cell $i . X_{m}, Z_{m}$ are the center of mass of the cylinder and $\mathrm{u}_{\mathrm{i}}, \mathrm{w}_{\mathrm{i}}$ the velocity at cell $\mathrm{i}$. Due to the axisymmetric geometry the tumble around the $\mathrm{x}$-axis as well as the swirl are negligible small compared to the dominant tumble in $y$-direction. Due to the symmetry of the engine and intake port geometry only a minor $\mathrm{X}$-tumble is formed resulting in almost no swirl flow structures.

In Fig. 14, the effect of the gas injection on the (a) Y-tumble level and (b) volume averaged velocity magnitude is illustrated. After IVO, a dominant clockwise rotating tumble flow structure arises, which decreases after reaching the maximum intake valve lift. At $\mathrm{BDC}$, the fuel injected through the upper two nozzle orifices is directed along the pent roof supporting the tumble flow structure which results in a peak for the tumble $\mathrm{Y}$ intensity right after $540{ }^{\circ} \mathrm{CA}$ as depicted by the blue curve. During the compression stroke, the tumble flow structures break down into smaller flow structures introducing additional turbulence into the engine cylinder. In order to assess the influence of the gas DI the results are compared to a second case where the direct injection has been deactivated. Without direct injection lower tumble numbers and volume averaged velocity magnitude can be seen after EOI. Due to the tumble break down, towards TDC the Y-tumble in the DI activated case decreases faster resulting in similar tumble numbers at TDC with and without direct injection. In contrast to this the velocity magnitude is right before start of combustion (SOC) in the DI activated case increased by $19 \%$.

In Fig. 15a the volume averaged subgrid-scale turbulent kinetic energy is depicted in order to further analyze the effect of tumble breakdown during compression. The direct injection introduces additional turbulence within the cylinder as shown by the blue peak at BDC for the DI activated case. Due to the early SOI the generated turbulence dissipates until spark timing and no major benefit can be expected for the ignition process. Nevertheless, in Fig. $15 \mathrm{~b}$ after $680^{\circ} \mathrm{CA}$ after BDC a slight increase in $k_{S G S}$ can be noticed for the DI activated case. As seen in Fig. 14, the DI enhances the overall mean flow magnitude and hence supporting the tumble flow motion. Thus, the tumble breakdown is delayed and occurs shortly before spark ignition, introducing additional turbulence right before combustion. When comparing the subgrid-scale turbulent kinetic energy of both DI activated and

(a)

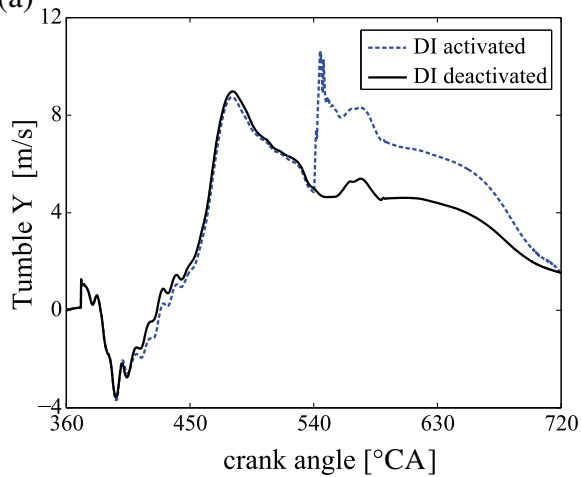

(b)

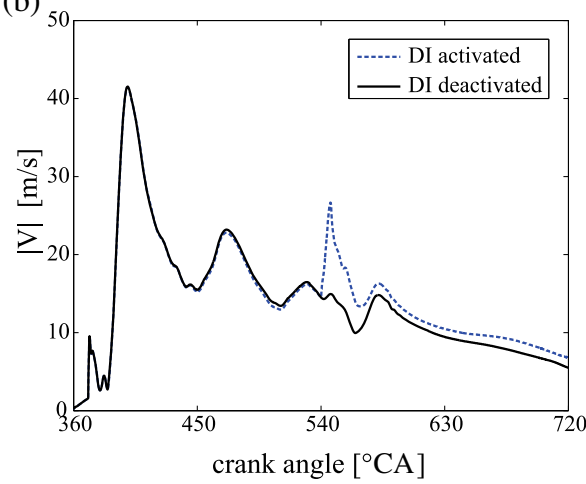

Fig. 14 Enhancement of in-cylinder flow magnitude through DI 

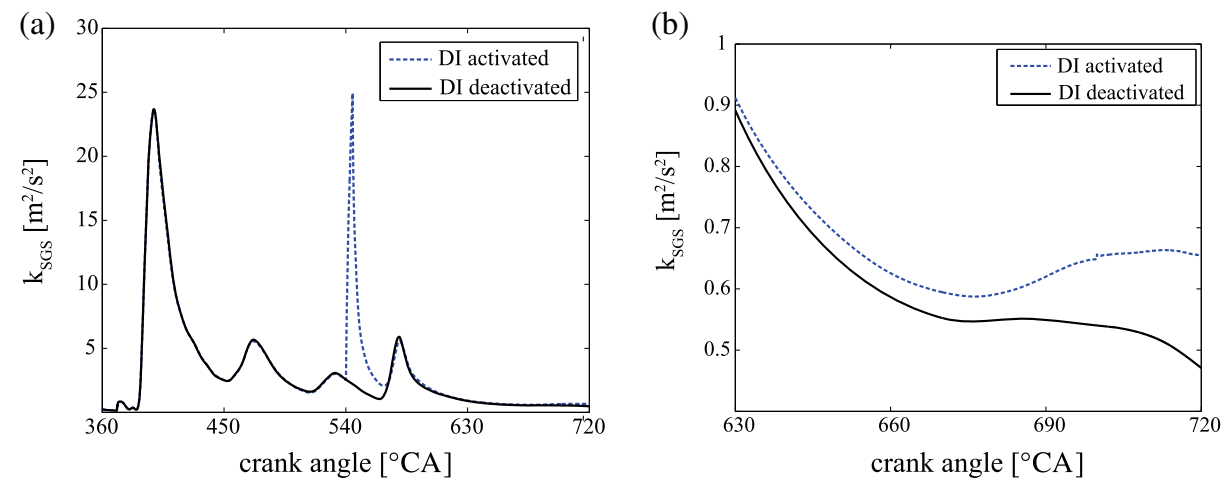

Fig. 15 Enhancement of in-cylinder flow magnitude through DI during the 1st cycle

DI deactivated cases right before SOC, the $k_{S G S}$ is $20 \%$ higher in case of DI. According to Eq. 4, turbulent flame is approximately increased by $7.9 \%$, which results in a faster combustion.

Measurements from the engine test bench also showed that injecting fuel along the pent roof region results in a stronger tumble flow, leading to a later breakdown shortly before SOC. The higher turbulence intensity at the early combustion stages enhances the flame propagation and hence results in a faster heat release in case of DI.

\subsection{Multiple cycle simulation}

\subsubsection{Comparison between simulation and experiment}

Figure 16a compares the experimental and numerical pressure traces. The average measured pressure is shown by the solid black line and the minima and maxima out of 144 cycles are the dashed black lines. The blue lines represent the single pressure traces of the LES simulation. The average pressure traces between simulation and experiment agree very well and all LES pressure curves are located within the experimental envelope. The maximum and

(a)

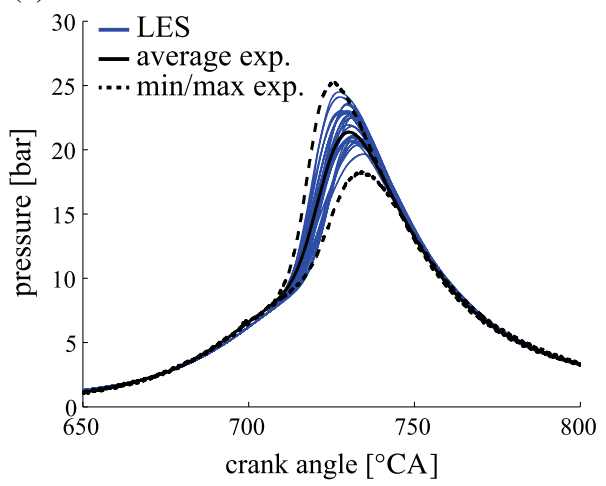

(b)

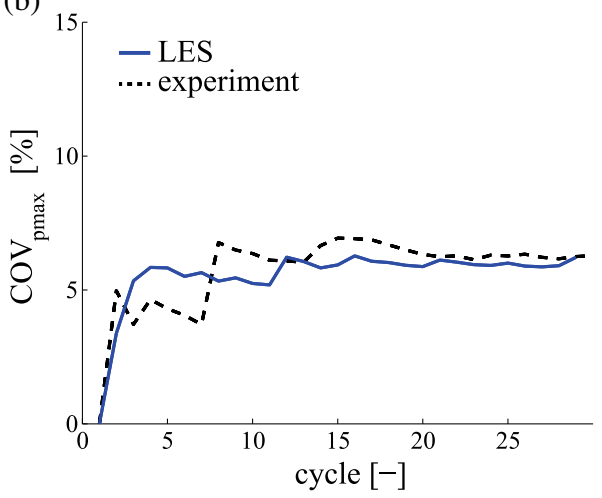

Fig. 16 a Comparison of the pressure traces between simulation and experiment; $\mathbf{b} \operatorname{COV}\left(p_{\max }\right)$ comparison between experiment and simulation, where the experimental $\operatorname{COV}\left(p_{\max }\right)$ value is around 0.059 after 144 cycles 
minimum pressure traces of the LES simulation shows a reasonable difference to the experimental profiles, which is attributed to the fewer number of simulated cycles ( 29 cycles). The coefficient of variance (COV) of the maximum pressure of the LES simulation and the experiment is shown in Fig. 16b. Both curves converge already after 15 cycles to a $C O V_{\text {pmax }}$ value of approximately $6 \%$, wheras the experimental $C O V_{p \max }$ value after 144 cycles is around $5.92 \%$.

\subsubsection{Impact of the direct injection on the CCV}

In [15] it was shown that for the studied perfectly premixed operation point, the observed $\mathrm{CCV}$ mainly result from differences in the cyclic turbulence and flow field. This agrees also with the findings in $[9,10]$, where a correlation between the central tumble position and the pressure maximum is shown. As shown in Fig. 15a the additional $\mathrm{k}_{S G S}$ due to injection is dissipated very fast and has no influence on the CCV behavior. Thus in the following the impact of the DI on cyclic differences in the large scale flow motions will be investigated.

Figure 17a shows the Y-tumble versus the piston position for eight selected cycles. The black line represents the Y-tumble number in case of deactivated gaseous DI. Already before direct injection cyclic differences of the tumble flow can be observed. During injection the tumble flow increases in all shown cycles and shows very similar evolutions. Figure $17 \mathrm{~b}$ shows the tumble numbers during injection in more detail. It can be seen that the cyclic differences between the shown cycles are preserved during and after the injection. This is illustrated by the red dashed lines which mark the line of the cycle with the highest and the lowest tumble number. This agrees well with the findings in [11], which reports relatively low influences of a spray on the occurring CCV. However the relative differences between the cycles are reduced, since the absolute cyclic differences are preserved while the total tumble level is increased.

Figure 18 illustrates the influence of the rate of decay of the Y-tumble between $660^{\circ}$ and $700{ }^{\circ} \mathrm{CA}$ on the cylinder averaged subgrid-scale turbulent kinetic energy at ignition timing $\left(699.8^{\circ}\right)$. A linear relation can be seen, since higher tumble gradients are followed by increased $\mathrm{k}_{S G S}$ values. The black dashed line is a linear regression curve and the $\mathrm{R}^{2}$ value of 0.6 indicates a strong correlation. In conclusion also the relative cyclic differences of the cylinder averaged $\mathrm{k}_{S G S}$ are reduced, since the tumble gradient shows a linear dependence on the subgrid-scale turbulent kinetic energy.

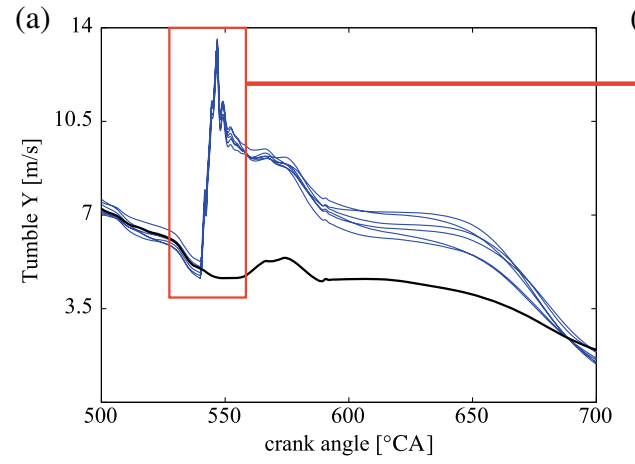

(b)

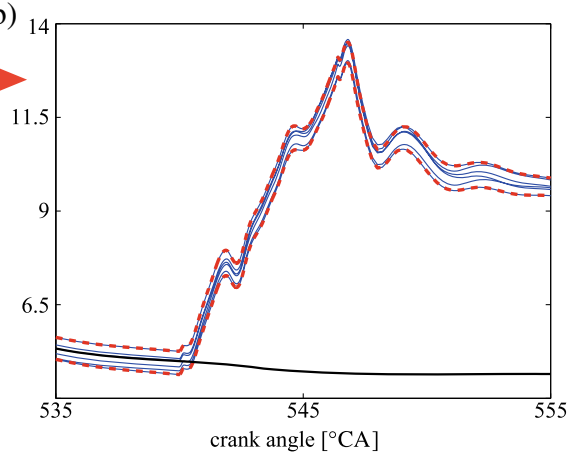

Fig. 17 Influence of the methane jet on the cycle-to-cycle variations. From $500^{\circ}-700{ }^{\circ} \mathrm{CA}$ (a) and from $535^{\circ}-555^{\circ} \mathrm{CA}(\mathbf{b})$ 
Fig. 18 Correlation between the cylinder averaged $k_{S G S}$ at spark timing and the rate of decay of the Y-tumble between $660^{\circ}$ to $700{ }^{\circ} \mathrm{CA}$

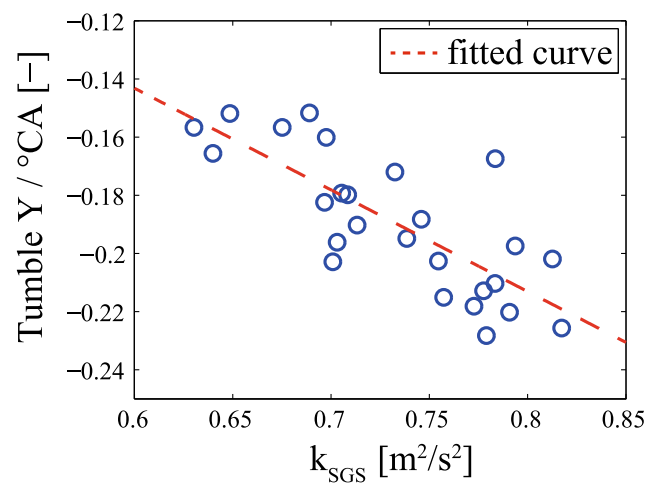

In general the gaseous injection showed to have no direct impact on the CCV but depending on the injection direction it influences the large scale flow structures. Thus, if the tumble is strengthened by the injection, relatively lower cyclic differences are expected. In contrast to this an injection direction which weakens the tumble flow is expected to increase the CCV. These observations agree well with the experimental data which show that for an injection direction supporting the tumble motion significantly lower CCVs are found compared to measurements with injection directions which lower the tumble levels.

Beside the turbulence also mixture formation can have an influence on the CCV behavior, since as shown in Fig. 12 the mixture is not perfectly mixed at SOI. In order to estimate the impact of cyclic mixture and turbulent variations on the flame propagation $\Phi$ and $\mathrm{k}_{S G S}$ are averaged in a sphere with a radius of $3 \mathrm{~mm}$ around the spark plug and the averages will be denoted as: \langle\rangle$_{S P}$. The averaged values close to the spark plug are chosen, since according to [15] the observed CCV correlate strongly with the early flame propagation. $\left\langle k_{S G S}\right\rangle_{S P}$ shows significantly larger variations $( \pm 26.5 \%)$ compared to $\langle\Phi\rangle_{S P}( \pm 7 \%)$. For the in this work applied combustion modeling $\langle\Phi\rangle_{S P}$ influences the laminar flame speed (3), while $\left\langle k_{S G S}\right\rangle_{S P}$ appears in the Damköhler correlation (4). Based on Eqs. 3 and 4 it can be seen that the cyclic variations of $\left\langle k_{S G S}\right\rangle_{S P}$ are followed by $\mathrm{s}_{T}$ variations of $\pm 10 \%$, while the cyclic differences of $\phi$ result in $\mathrm{s}_{T}$ variations of $\pm 3 \%$. The same trend can also be seen for averages in the full cylinder. Thus for the current setup and operation point the influence of $\mathrm{k}_{S G S}$ on the CCV is significantly larger compared to variations of $\Phi$.

\section{Conclusions}

In this work the flow field evolution and the combustion process in a direct injected methane-fuelled engine are simulated using LES. The combustion was modeled by a level set approach using the laminar flame speed model by Gülder and the turbulent flame speed closure by Damköhler, while the supersonic direct injection is simulated based on the aritficial inlet boundary (AIB) approach proposed in Müller et al. [1].

In the first part the sensitivity of the results on grid resolution and discretization order are investigated. An initial grid resolution study revealed a low sensitivity of the subgrid-scale turbulent kinetic energy $k_{S G S}$ for the three calculated meshes. Only in the jet breakup of the incoming air during the intake stroke an influence of the grid resolution was observed. Compared to the resolution, the discretization order showed a stronger effect on the calculated $k_{S G S}$. In general a lower discretization order was found to exhibit a smoothing effect which reduces the computed subgrid-scale turbulent kinetic energy, as expected. 
Although discrepancies in the cylinder averaged values for $k_{S G S}$ for the three resolutions investigated amounted to less than $25 \%$, the differences have a strong impact on the local turbulent flame speed. With the default Damköhler correlation employed, two opposing trends were observed for the flame propagation with LES: Due to the partially resolved turbulence field the turbulent flame speed decreases since it is proportional to $k_{S G S}$ (in the case of RANS proportional to $k$ ). Conversely, the resolved turbulence scales in the LES simulation substantially increase the flame area, which promotes flame propagation. These two effects reduce the influence of the grid resolution on reactive LES engine calculations with G-equation. Based on these findings a method based on the comparison of $k_{S G S}$ with $k$ is proposed which enables efficient adjustment of the modelling constant in the turbulent flame speed equation for LES based on a single RANS simulation.

The second part of the paper focuses on the impact of the gaseous DI on the flow field and the $\mathrm{CCV}$ behavior. For the chosen injector orientation and the chosen early injection timing the majority of the fuel impinges on the cylinder wall on the opposite side and in the following the tumble motion transports the fuel rich zone back to the injector position, resulting in a stratified mixture at ignition timing. The turbulence created by the early direct methane injection, was found to dissipate quickly and has no influence on the later combustion. In contrast to this, the interaction between the gaseous direct injection and the tumble motion has a strong impact on the flame propagation, since the kinetic energy stored in the tumble motion is released in form of small scale turbulence close to TDC when the tumble breaks down.

The multiple cycle simulation showed to well reproduce the average pressure trace and the cyclic fluctuations of the experiment, indicating that the simulation setup is capable of capturing the impact of the injection event on the multiple cycle behavior. The influence of the gaseous DI on the cycle-to-cycle variations is mainly connected to its interaction with the tumble motion: during the gaseous injection the cyclic differences in the tumble motion were preserved, but the global tumble level is influenced depending on the injection direction. The differences in the global tumble level showed to strongly correlate with the turbulent kinetic energy, which according to [15] strongly influences the CCV. Thus if the injection direction is adjusted to strengthen the tumble flow, relatively lower CCV are expected. In contrast to this if the methane injection weakens the tumble flow motion, relatively higher $\mathrm{CCV}$ are expected. This finding agrees with experimental results, which show significantly lower CCVs in case of a methane injection in tumble direction. Compared to variations in the subgrid turbulence levels, fluctuations of the equivalence ratio in the spark plug vicinity showed only a minor effect on the observed CCVs for the studied operating condition and engine geometry.

For future work the injection direction and timing will be varied in order to investigate if modeling approach is able to predict its influence on the CCVs.

Acknowledgments Financial support of the Swiss Federal Office of Energy (BFE), project number SI/500644 is gratefully acknowledged. The experimental data was acquired during the CLEVER project, supported by the Swiss Federal Office of Energy (BFE), by the Swiss Federal Office for the Environment (FOEN), by Novatlantis, by the Swiss Society for Gas and Water (SVGW), and by the German Technical and Scientific Association for Gas and Water (DVGW). The authors acknowledge Volkswagen AG Research and Robert Bosch $\mathrm{GmbH}$ for technical support and David Mauke for performing the experiments.

\section{Appendix 1}


Table 3 Adjusted AIB parameters for current operating point

\begin{tabular}{ll}
\hline Pressure & $8.6 \mathrm{bar}$ \\
Temperature & $133.6 \mathrm{~K}$ \\
$\mathrm{k}$ & $0 \mathrm{~m}^{2} / \mathrm{s}^{2}$ \\
\hline
\end{tabular}

\section{Derivation of the AIB constants for the observed operation point}

In the previous work of Müller et al. [1], a 3-step methodology has been used to derive the AIB conditions (see Table 3). As described below, the following parameters for the Simple Box (for explanation, see [1]) inlet boundary condition have been adjusted to fit the simulation results from the detailed LES underexpansion simulation:

1. Determine the normal velocity component $U_{N}$ by adjusting the jet penetration depth

2. Adjust the inlet mass flow rate $\dot{m}_{\text {Nozzle }}$ according to experimental measurement data

3. Adjust the turbulence parameters to reproduce the turbulent kinetic energy field

Figure 19 addresses the first task which is the adjustment of the penetration depth. The radial mean methane concentration has been averaged over 100 bin sections in flow direction. In order to guarantee the same fuel penetration, the normal velocity magnitude of the Simple Box model has been adjusted to meet the experimentally validated LES underexpansion fuel injection result. The validation of the velocity magnitude, the mixture fraction and the sub grid turbulence are shown in Figs. 20 and 21.

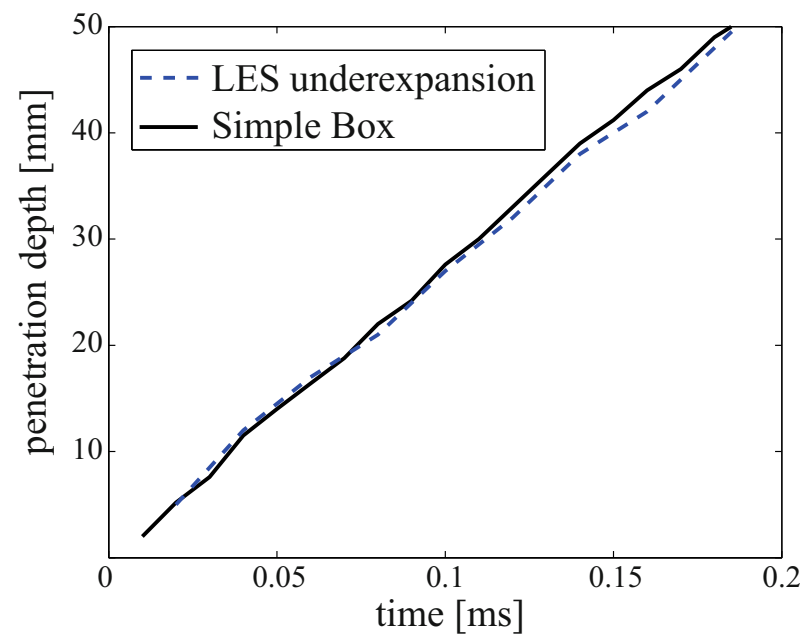

Fig. 19 Validation of the penetration depth for injected gaseous fuel 
$\mathrm{z}$ - axis $[\mathrm{mm}]$
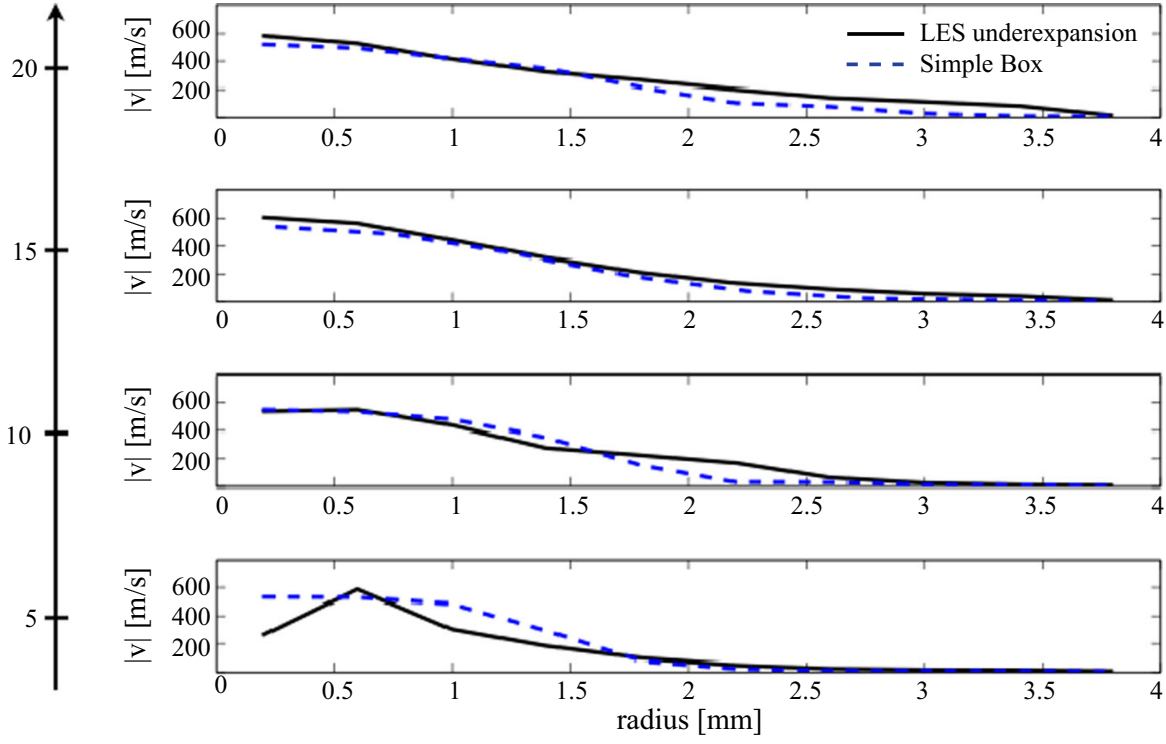

(a) Velocity magnitude

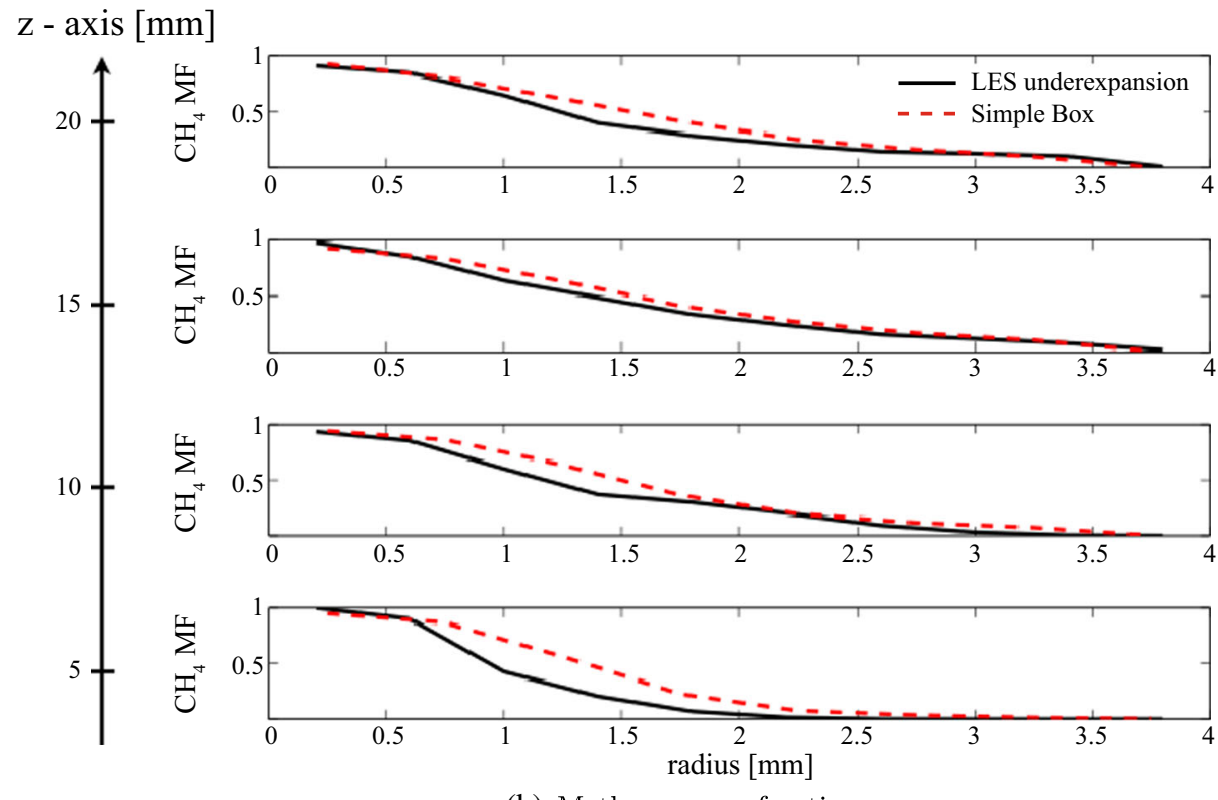

(b) Methane mass fraction

Fig. 20 Validation of the radial averaged velocity magnitude and methane mass fraction line distributions at $\mathrm{t}=0.12 \mathrm{~ms}$ for different downstream locations 


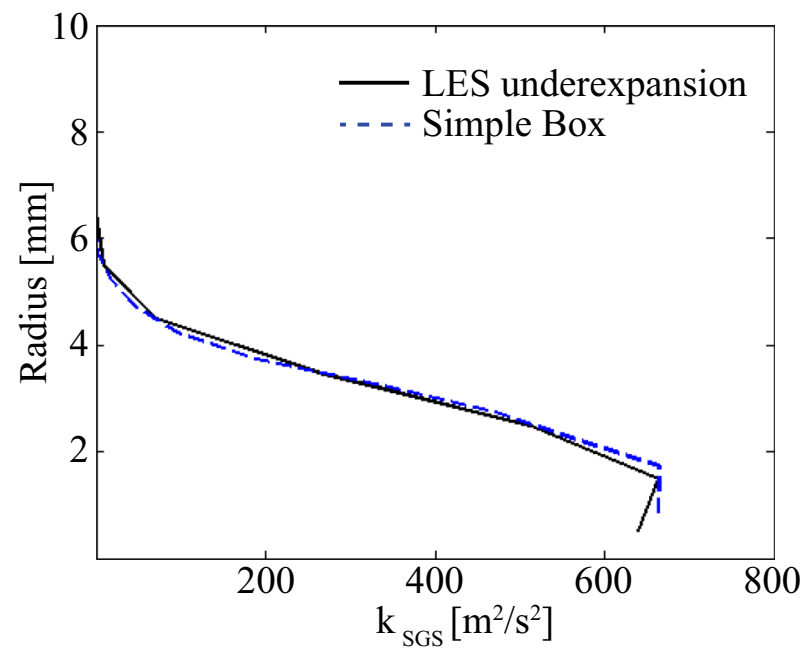

Fig. 21 Validation of the radial averaged subgrid-scale turbulent kinetic energy at downstream location $\mathrm{z}=$ $25 \mathrm{~mm}$ and $\mathrm{t}=0.12 \mathrm{~ms}$

\section{References}

1. Müller, F., Schmitt, M., Wright, Y.M., Boulouchos, K.: Determination of Supersonic Inlet Boundaries for Gaseous Engines Based on Detailed RANS and LES Simulations. SAE Int. J. Engines, No. 2013-240004 (2013)

2. Heywood, J.: Internal Combustion Engine Fundamentals. McGraw-Hill (1988)

3. D' Errico, G.D., Onorati, A., Ellgas, S., Obieglo, A.: Thermo-Fluid Dynamic Simulation of a S.I. Single-Cylinder $\mathrm{H}_{2}$ engine and Comparison with experimental data. In: Proc. ICES2006 ASME Internal Combustion Engine Division, Spring technical Conference (2006)

4. Gerke, U., Boulouchos, K.: Three-dimensional computational fluid dynamics simulation of hydrogen engines using a turbulent flame speed closure model. Int. J. Engine Res. 13(5), 464-481 (2012)

5. Liu, F.: CFD Study on Hydrogen Engine Mixture Formation and Combustion, PhD thesis, Technical University of Cottbus (2004)

6. Sukumaran, S., Kong, S.: Numerical study on mixture formation characteristics in a direct-injection hydrogen engine. Int. J. Hydrog. Energy 35, 7991-8007 (2010)

7. Gerke, U.: Numerical analysis of Mixture Formation and Combustion in a Hydrogen Direct-Injection Internal Combustion engine, $\mathrm{PhD}$ thesis ETH No. 17477. Cuvillier Verlag (2007)

8. Rutland, C.J.: Large-eddy simulations for internal combustion engines - a review. Int. J. Engine Res. 12, 1-31 (2011)

9. Enaux, B., Granet, V., Vermorel, O., Lacour, C., Pera, C., Angelberger, C., Poinsot, T.: LES study of cycle-to-cycle variations in a spark ignition engine. Proc. Combust. Inst. 33, 3115-3122 (2010)

10. Granet, V., Vermorel, O., Lacour, C., Enaux, B., Dugu, V., Poinsot, T.: Large-Eddy Simulation and experimental study of cycle-to-cycle variations of stable and unstable operating points in a spark ignition engine. Combust. Flame 159(4), 1562-1575 (2012)

11. Goryntsev, D., Sadiki, A., Janicka, J.: Towards large eddy simulation of spray combustion in direct injection spark ignition engine. SAE Technical Paper 2011-01-1884 (2011)

12. Haworth, D.C.: Large-Eddy Simulation of in-cylinder flows. Oil Gas Sci. Technol. 2, 175-185 (1999)

13. Vermorel, O., Richard, S., Colin, O., Angelberger, C., Benkenida, A., Veynante, D.: Towards the understanding of cyclic variability in a spark ignited engine using multi-cycle LES. Combust. Flame 156(8), 1525-1541 (2009) 
14. Fontanesi, S., d'Adamo, A., Rutland, C.J.: Large-Eddy simulation analysis of spark configuration effect on cycle-to-cycle variability of combustion and knock. Int. J. Engine Res.earch, 1468087414566253 (2015)

15. Koch, J., Schmitt, M., Wright, Y.M., Steurs, K., Boulouchos, K.: LES multi-cycle analysis of the combustion process in a small SI engine. SAE Int. J. Engines, No. 2014-01-1138 (2014)

16. Granet, V., Vermorel, O., Lacour, C., Enaux, B., Dugu, V., Poinsot, T.: Large-Eddy Simulation and experimental study of cycle-to-cycle variations of stable and unstable operating points in a spark ignition engine. Combust. Flame 159(4), 1562-1575 (2012)

17. Adamson, C., Nicholls, A.: On structure of jets from highly underexpandednozzle into still air. J. Aerosol Sci. 26, 16-24 (1959)

18. Young, W.S.: Derivation of the free-jet Mach-disk location using the entropy-balance principle. Phys. Fluids 18(11), 1421-1425 (1975)

19. Vuorinen, V., Yu, J., Tirunagari, S., Kaario, O., Larmi, M., Duwig, C., Boersma, B.J.: Large-eddy simulation of highly underexpanded transient gas jets. Phys. Fluids 25, 016101 (2013)

20. Pope, S.B.: Turbulent flows. Cambridge University Press, Cambridge (1975)

21. Butler, T.D., O'Rourke, P.J.: A numerical method for two-dimensional unsteady reacting flows. Proc. Combust. Inst. 16, 1503-1515 (1977)

22. Angelberger, C., Veynante, D., Egolfopoulos, F.: LES of Chemical and Acoustic Forcing of a Premixed Dump Combustor. Flow Turbul. Combust. 65, 205-222 (2000)

23. Pitsch, H., Duchamp De Lageneste, L.: Large-Eddy simulation of premixed turbulent combustion using a level-set approach. Proc. Combust. Inst. 29, 2001-2008 (2002)

24. Williams, F.A.: Turbulent combustion. In: Buckmaster, J.D. (ed.) The Mathematics of Combustion. SIAM (1985)

25. Peters, N.: The turbulent burning velocity for large scale and small scale turbulence. J. Fluid Mech. 384, 107-132 (1999)

26. Gülder, O.L.: Turbulence premixed flame propagation models for different combustion regimes. In: 23rd Symp. (Int.) on Combustion, The Combustion Institute, pp. 743-750 (1990)

27. CD-adapco: Methodology StarCD Version 4.14 (2010)

28. Goryntsev, D., Sadiki, A., Janicka, J.: Cycle-to-cycle variations based unsteady effects on spray combustion in internal combustion engines by using LES. SAE Technical Paper 2012-01-0399 (2012)

29. Richard, S., Colin, O., Vermorel, O., Benkenida, A., Angelberger, C., Veynante, D.: Towards large eddy simulation of combustion in spark ignition engines. Proc. Combust. Inst. 31(2), 3059-3066 (2007)

30. Colin, O., Truffin, K.: A spark ignition model for large eddy simulation based on an FSD transport equation (ISSIM-LES). Proc. Combust. Inst. 33(2), 3097-3104 (2011)

31. Dahms, R.N., Drake, M.C., Fansler, T.D., Kuo, T.W., Peters, N.: Understanding ignition processes in spray-guided gasoline engines using high-speed imaging and the extended spark-ignition model sparkcimm. part a: Spark channel processes and the turbulent flame front propagation. Combust. Flame 158(11), 2229-2244 (2011)

32. Soltic, P., Egli, R., Mauke, D., Wright, Y.M., Bach, C., Boulouchos, K.: Flow, mixture formation and combustion in a methane direct injection engine for Lambda $=1$. In: Proceedings of 6th Gas Engine Conference, Stuttgart, October 26-27 (2011)

33. Goryntsev, D., Sadiki, A., Klein, M., Janicka, J.: Large eddy simulation based analysis of the effects of cycle-to-cycle variations on air-fuel mixing in realistic DISI IC-engines. Proc. Combust. Inst. 32, 2759 2766 (2009)

34. Fontanesi, S., Paltrinieri, S., D’Adamo, A., Duranti, S.: Investigation of boundary condition and field distribution effects on the cycle-to-cycle variability of a turbocharged gdi engine using LES, oil and gas science and technology. IFP Energies nouvelles (2014) 